 \\ z Filologii Polskiej i Słowiańskiej
}

DOI: $10.11649 /$ sfps.2018.006

\author{
Цветелина Георгиева
}

(Институт за български език „Проф. Любомир Андрейчин“ при Българската академия на науките)

\section{Семантичен речник на роднинските названия в българския език}

Идеята за създаване на семантичен речник на роднинските названия е реализирана в Приложение № 1 на моята монография Родството и роднинските названия в българския език (семантика и лексикографско представяне) (Георгиева, 2016а) - първото цялостно изследване, в което съвкупността от всички единици от лексикалносемантичното поле 'роднини' е представена като структура със сложна организация и с богат състав, при това в пряка връзка с родствената система на българите, а самите езикови единици, назоваващи определени или неопределени референти (съответно майка, син, съпрузи и др. и роднина, потомък, деди и др.), се разглеждат от различни ракурси с оглед на мястото им в езиковата система и в текста. Всъщност монографията включва четири приложения: Приложение № 1 Семантичен речник на елементарните и неелементарните роднински названия, назоваващи конкретни тица, който тук ще бъде обект на по-детайлно представяне, Приложение № 2

This is an Open Access article distributed under the terms of the Creative Commons Attribution 3.0 PL License (creativecommons.org/licenses/by/3.0/pl/), which permits redistribution, commercial and non-commercial, provided that the article is properly cited. (c) The Author(s) 2018.

Publisher: Institute of Slavic Studies, Polish Academy of Sciences

[Wydawca: Instytut Slawistyki Polskiej Akademii Nauk] 
Примерни речникови статии на същински и несъщински роднински названия, Приложение № 3 Примерен словник на едносъставни роднински названия на тица с крбвно родство и Приложение № 4 Примерен словник на едносъставни роднински названия на тица с некръвно родство. Приложенията следхождат аналитичната част, която включва представяне на теоретичните основи и използваната методология, описание на системата на родство у българите и названията за родство в българския език, характеристика на роднинските названия (PH) и на системата от $\mathrm{PH}$ в българския език (БЕ), както и семантичен анализ на РН. Трябва да се посочи, че четирите приложения са естествено продължение и обобщение под друга (структурирана) форма на предхождащото изложение.

В основата на изготвянето на Семантичния речник стои идеята да се разграничат няколко „лексикографски типа“ $\mathrm{PH}$, а информацията в него да бъде представена в табличен вид и да се структурира по следните три параметъра:

\section{1. параметър - цифров код на референта;}

2. параметър - елементарна/неелементарна реверсивна семема;

\section{3. параметър - езиков знак, представящ референта.}

Речникът е организиран в посока от цифровия код, зает от енциклопедичния речник Българска семейно-родова лексика на Хр. Холиолчев, М. Младенов и Л. Радева (БСРЛ, 2012), през метаезик във формата на дефиниция, поставена в горни кавички ('), до самия езиков знак. В 7 таблици (вж. и по-долу) са предложени модели за речниково представяне на названия на роднини - мъже, жени, деца и двойки лица - чрез използването на два вида реверсивни семеми (елементарни и неелементарни), които се въвеждат за първи път в монографията.

Под реверсивна семема се разбира семемата, която представя описвания референт от релационната двойка субекти $X-Y$ с оглед на съществуващата между тях двупосочност. Обикновено тази семема е представена в речниците чрез дефиниция, при която един субект се съотнася с друг субект по модела $X$ по отношение на $Y$. Този модел е предпочитан от лексикографите (вж. Таблици № 1, № 2 , № 5 , № 6 и № 7). ${ }^{1}$

1 В монографията са въведени и термините нереверсивна и конверсивна семема. Нереверсивна е семемата, която представя същия референт с оглед на заявена еднопосочност. Използва се моделът $X$ има $Y$ (срв. майка... 1. ... 2. Жена, която има дете.). 
Към втория параметьр в Семантичния речник са представени конкретните елементарни и неелементарни реверсивни семеми на $\mathrm{PH}$, назоваващи определени лица. Елементарни реверсивни семеми са семемите, при които описваният референт се дефинира без конектор, т.е без свързващо лице (такива са семемите на майка (срв. Его - майка), още на баща, брат, дъщеря и др. - вж. Таблици № 1 и № 2). Неелементарни реверсивни семеми са семемите, при които описваният референт се дефинира с конектор (такива са семемите на вуйчо (конекторът е майка, срв. Его - майка - вуйчо), още на племенник, тъща, зблва и др. (вж. Таблици № 3 и № 4, както и Таблици № 5, № 6 и № 7). Първият тип семеми може да се определят като прости, а вторият - като сложни. Самите езиковите единици, дефинирани чрез тези семеми, се определят в монографията съответно като прости (елементарни) PН и сложни (неелементарни) РН (вж. още заглавията на таблиците).

Във връзка с първия и третия параметър трябва да се отбележи, че в монографията се прави разграничение между терминологичните съчетания роднински термини и роднински названия (често използвани в научната литература като синоними, без да се уточнява какво съдържание се влага в тях). Съчетанието роднински названия тук се употребява за единици от естествения език като майка, баба, диалектните калимана 'кума', уйко 'вуйчо', мачева 'мащеха' и др., защото те нямат тясно специализиран характер и не отговарят на нужните изисквания за термини (вж. дефинирането на термин у Попова, 2012). Към третия параметър от Речника са посочени подобни единици, определени като представителни главно общоупотребими, а там, където такива липсват - диалектни (сред знак о). Пълният списък на тези единици е изготвен след предварително обобщение на езиковия материал в БСРЛ (2012) за определяне на конкретни референти роднини, за които в БЕ има поне едно $\mathrm{PH}$.

Наблюденията сочат, че съществува колебание при представянето на тази семема дори в рамките на един речник - тя се определя или като отделно значение, или като нюанс към реверсивната семема. Конверсивна е семемата, която представя референта от гледна точка на субекта Y. Чрез нея се заявява възможната обратимост в посесивното отношение. Конверсивната семема се дефинира по модела моят/mвоят ..., т.е. с оглед на Eгото (напр. в изречението Майка излезе навън РН майка е със значение 'моята майка'). Тази семема рядко се посочва в речниците (открива се напр. при мама 'моята майка', татко 'моят баща'). Примерите за този вид семема обикновено се привеждат като илюстрация на реверсивната, което е некоректно, тъй като конверсивната семема е свързана с прагматиката на езиковия знак. 
Съчетанието роднински термин (идеален термин) тук се използва само за единици от изкуствен език (разграничението е съобразено с класификацията на термините на реални и идеални, направена от М. Попова вж. Попова, $2012^{2}$ ). Във връзка с описанието на роднинските отношения в областта на етнологията и етнографията, както и на съвременната лексикография, са правени съзнателни опити от различни специалисти да бъдат създадени неезикови знаци, които да се характеризират с признака междуезиковост. По този начин на всеки конкретен референт съответства един универсален код - т.нар. в монографията идеален термин.

Тези неезикови знаци може да се представят обобщено като:

- буквени кодове - напр. за Л. Г. Морган такива са инициалните символи на английските названия за роднини, които и до днес се ползват от изследователите, напр. F за 'баща', $S$ за 'сестра' и др. (Морган, 1877/1939); Ю. И. Левин използва буквени индекси и стрелки - Д за 'дете', Р за 'родител', С за 'съпруг', Э за 'Его', $\mathcal{м}$ за мъжки пол, ж за женски пол, $\uparrow$ за по-голям, $\downarrow$ за по-малък (Левин, 1970) и

- ицфрови кодове - С. А. Токарев (през 20-те год. на ХХ в.) предлага цифрова номерация за 8 основни референта: 1 за 'баща', 2 за 'майка', 3 за 'син', 4 за 'дъщеря', 5 за 'съпруг', 6 за 'съпруга', 7 за 'брат' и 8 за 'сестра'; Хр. Холиолчев предлага по-пълна и различна кодировка, състояща се също от цифри и символи - вж. БСРЛ (2012) и Георгиева (2016b).

Първият параметьр в Семантичния речник представя цифровия код, въведен от Хр. Холиолчев, с лека модификация: въведен е нов символ - черна точка $(\bullet)$, която се използва в някои случаи вместо символа черен ромб ( $)$ с цел разграничаване на различни референти (срв. брат 3 , полубрат $3^{\bullet}$ и побратим $33^{\star}$ с сестра 4 , полусестра $4^{\bullet}$ и посестрима 4 ; син 5 , доведеник 5` и завареник 5॰; дъщеря 6, доведенииа 6` и заваренииа 6•).

Елементарната реверсивна семема на РН в Таблици № 1 и № 2 е построена по модела $X$ по отношение на $Y$, където първата част на дефиницията е представена винаги просто - като 'лице от мъжки/женски пол', т.е. без употребата на РН, за да не се получи кръговост (каквато се забелязва в някои

${ }^{2}$ Реалните термини се отклоняват от предписанията на теорията на терминологията и с течение на времето се характеризират с многозначност, синонимия и дори стилистична обагреност, докато идеалните термини, които са елементи от езиковата система, са рядко срещани в практиката; по-постижимо е създаването на идеални термини, които са знаци от изкуствен език - вж. Попова, 2012, сс. 79, 80. 
речници при дефинирането напр. на брат). Втора част (изписаното в италик) представя референта/референтите, спрямо които това лице се съотнася.

\section{Таблица 1. Елементарни РН за лица от мъжки пол}

\begin{tabular}{|c|c|c|}
\hline $\begin{array}{l}\text { Цифров } \\
\text { код на } \\
\text { референта }\end{array}$ & Елементарна реверсивна семема, представяща референта & $\begin{array}{c}\text { Езиков знак, } \\
\text { представящ } \\
\text { референта }\end{array}$ \\
\hline 1 & $\begin{array}{c}\text { 'лице от мъжки пол по отношение на собствените си } \\
\text { деца' }\end{array}$ & бащза \\
\hline $1 \triangleleft$ & $\begin{array}{c}\text { 'лице от мъжки пол по отночение на децата от друг } \\
\text { брак на своята жена' }\end{array}$ & пастрок \\
\hline 3 & $\begin{array}{c}\text { 'лице от мъжки пол по отношение на другите деца } \\
\text { в семейството, с които то има едни и същз (заедно или } \\
\text { поотделно) родители' }\end{array}$ & бpam \\
\hline $3 \bullet$ & $\begin{array}{c}\text { 'лице от мъжки пол по отномение на друго лице, с което } \\
\text { то има един обш родител' }\end{array}$ & полубрат \\
\hline $3 \bullet$ & $\begin{array}{c}\text { 'лице от мъжки пол по отночение на някого, с когото го } \\
\text { свбрзва родство след специален обред - смесване на крвв } \\
\text { от вените, клетва' }\end{array}$ & побратим \\
\hline 5 & 'лице от мъжки пол по отношение на родителите си' & син \\
\hline $5.9 \bullet \sim 89 \bullet$ & $\begin{array}{c}\text { 'лице от мъжки пол (обикн. момък, момче) по отноше- } \\
\text { ние на обредното тице, което го е крбстило' }\end{array}$ & крвщелник \\
\hline 7 & $\begin{array}{c}\text { 'лице от мъжки пол по отночение на жената, с която } \\
\text { е в брачна връзка' }\end{array}$ & conpyz \\
\hline $7 \bullet$ & $\begin{array}{c}\text { 'лице от мъжки пол (обикн. момък, момче), обичайно } \\
\text { обвързано с жена (обикн. мома, девойка) с уговорка за } \\
\text { женитба' }\end{array}$ & годеник \\
\hline 9 & $\begin{array}{c}\text { 'лице от мъжки пол (обредно лице) по отночение на } \\
\text { двойката лица, на които е брачен свидетел' }\end{array}$ & $\kappa y M$ \\
\hline $9 \bullet$ & $\begin{array}{c}\text { 'лице от мъжки пол (обредно лице) по отночение на } \\
\text { крбстеното от него лице' }\end{array}$ & $к р ә с т н и к$ \\
\hline 99 & $\begin{array}{l}\text { 'лице от мъжки пол по отношение на обредните лица, } \\
\text { които са го венчали' }\end{array}$ & кумеи \\
\hline
\end{tabular}

\section{Таблица 2. Елементарни РН за лица от женски пол}

\begin{tabular}{|c|c|c|}
\hline $\begin{array}{l}\text { Цифров } \\
\text { код на } \\
\text { референта }\end{array}$ & Елементарна реверсивна семема, представяща референта & $\begin{array}{c}\text { Езиков знак, } \\
\text { представящ } \\
\text { референта }\end{array}$ \\
\hline 2 & $\begin{array}{c}\text { 'лице от женски пол по отночение на собствените си } \\
\text { деца' }\end{array}$ & майка \\
\hline $2 \bullet$ & $\begin{array}{c}\text { 'лице от женски пол по отношение на децата от друг } \\
\text { брак на своя мбж' }\end{array}$ & мащеха \\
\hline 4 & $\begin{array}{c}\text { 'лице от женски пол по отношение на другите деца } \\
\text { в семейството, с които то има едни и същи (заедно или } \\
\text { поотделно) родители' }\end{array}$ & cecmpa \\
\hline
\end{tabular}




\begin{tabular}{|c|c|c|}
\hline $\begin{array}{l}\text { Цифров } \\
\text { код на } \\
\text { референта }\end{array}$ & Елементарна реверсивна семема, представяща референта & $\begin{array}{c}\text { Езиков знак, } \\
\text { представящ } \\
\text { референта }\end{array}$ \\
\hline $4^{\bullet}$ & $\begin{array}{c}\text { 'лице от женски пол по отношение на друго тице, } \\
\text { с което то има един общ родител' }\end{array}$ & полусестра \\
\hline $4 \triangleleft$ & $\begin{array}{c}\text { 'лице от женски пол по отношение на някого, с когото го } \\
\text { свързва родство след специален обред - смесване на крвв } \\
\text { от вените, клетва' }\end{array}$ & посестрима \\
\hline 6 & 'лице от женски пол по отношение на родителите си' & двщеря \\
\hline $6.9 \diamond \sim 89 \bullet$ & $\begin{array}{c}\text { 'лице от женски пол (обикн. девойка, момиче) по отно- } \\
\text { шение на обредното лице, което го е крғстило' }\end{array}$ & крвщелница \\
\hline 8 & $\begin{array}{c}\text { 'лице от женски пол по отночение на мбжа, с когото е в } \\
\text { брачна врбзка' }\end{array}$ & conpyza \\
\hline $8 \bullet$ & $\begin{array}{c}\text { 'лице от женски пол (обикн. мома, девойка), обичайно } \\
\text { обвързано с мбж (обикн. момбк, ерген) с уговорка за } \\
\text { женитба' }\end{array}$ & годеница \\
\hline 8.99 & $\begin{array}{c}\text { 'лице от женски пол по отношение на обредните лица, } \\
\text { които са го венчали' }\end{array}$ & кумица \\
\hline 89 & $\begin{array}{c}\text { 'лице от женски пол (обредно лице) по отношение на } \\
\text { двойката лица, на които е брачен свидетел' }\end{array}$ & кума \\
\hline $89 \bullet$ & $\begin{array}{c}\text { 'лице от женски пол (обредно лице) по отношение на } \\
\text { крбстеното от него лице' }\end{array}$ & крәстница \\
\hline
\end{tabular}

Неелементарната реверсивна семема на РН в Таблици № 3 и № 4 е построена по модела $X$ на $Y$, където $X$ е винаги просто (елементарно) $\mathrm{PH}$, докато $Y$ (изписаното в италик) може да бъде не само просто (напр. при референт с цифров код 11, 12, 17, 18, 31, 32, 21, 22, 27, 28, 41, 42 и др.), но и сложно РН (напр. при референт с цифров код 111, 176, 185, 531, 547, 276, 647, 832, 837 и др.).

\section{Таблица 3. Неелементарни РН за лица от мъжки пол}

\begin{tabular}{|c|c|c|}
\hline $\begin{array}{c}\text { Цифров } \\
\text { код на } \\
\text { референта }\end{array}$ & Неелементарна реверсивна семема, представяща референта & $\begin{array}{c}\text { Езиков знак, } \\
\text { представящ } \\
\text { референта }\end{array}$ \\
\hline 11 & 'баща на бащата' & дядо \\
12 & 'баща на майката' & дядо \\
17 & 'баща на съпруга' & свеквр \\
18 & 'баща на съпругата' & тәст \\
31 & 'брат на бащата' & чичо \\
32 & 'брат на майката' & вуйчо \\
37 & 'брат на съпруга' & девер \\
38 & 'брат на съпругата' & иурей \\
\hline
\end{tabular}




\begin{tabular}{|c|c|c|}
\hline $\begin{array}{c}\text { Цифров } \\
\text { код на } \\
\text { референта }\end{array}$ & Неелементарна реверсивна семема, представяща референта & $\begin{array}{c}\text { Езиков знак, } \\
\text { представящ } \\
\text { референта }\end{array}$ \\
\hline 53 & 'син на брата' & племенник \\
\hline 54 & 'син на сестрата' & племенник \\
\hline 55 & 'син на сина' & внук \\
\hline 56 & 'син на дъщерята' & внук \\
\hline 74 & 'съпруг на сестрата' & зem \\
\hline 76 & 'съпруг на дъщерята' & зem \\
\hline 111 & ‘баща на бащата на бащза; баща на дядото (по баща)’ & прадядо \\
\hline 112 & ‘баща на бащзата на майка; баща на дядото (по майка)’ & прадядо \\
\hline 121 & ‘баща на майката на баща; баща на бабата (по баща)’ & прадядо \\
\hline 122 & ‘баща на майката на майка; баща на бабата (по майка) & прадядо \\
\hline 176 & 'баща на зетя’ & cвam \\
\hline 185 & 'баща на снахата' & cвam \\
\hline 311 & ‘брат на бащата на бащ, ; брат на дядото (по баща) & ○ пречича \\
\hline 531 & 'син на брата на бащза; син на чичото' & братовчед \\
\hline 532 & 'син на брата на майка; син на вуйчото' & братовчед \\
\hline 537 & 'син на брата на съпруг; син на девера' & ○ деверичник \\
\hline 541 & 'син на сестрата на бащза; син на лелята (по баща)' & братовчед \\
\hline 542 & 'син на сестрата на майка; син на лелята (по майка)' & братовчед \\
\hline 547 & 'син на сестрата на съпруг; син на зълвата' & О зблвичник \\
\hline 555 & 'син на сина на син' & правнук \\
\hline 556 & 'син на сина на дъщеря’ & правнук \\
\hline 565 & 'син на дъщерята на син' & правнук \\
\hline 566 & 'син на дъщерята на дъщеря' & правнук \\
\hline 741 & 'съпруг на сестрата на башза' & олелин \\
\hline 742 & 'съпруг на сестрата на майка' & ○ тетин \\
\hline 747 & 'съпруг на сестрата на съпруг; сыпруг на зълвата' & О зблвеник \\
\hline 748 & 'съпруг на сестрата на съпругата' & баджанак \\
\hline
\end{tabular}

Таблица 4. Неелементарни РН за лица от женски пол

\begin{tabular}{|c|c|c|}
\hline $\begin{array}{c}\text { Цифров } \\
\text { код на } \\
\text { референта }\end{array}$ & Неелементарна реверсивна семема, представяща референта & $\begin{array}{c}\text { Езиков знак, } \\
\text { представящ } \\
\text { референта }\end{array}$ \\
\hline 21 & 'майка на бащата' & баба \\
22 & 'майка на майката' & баба \\
27 & 'майка на сбпруга' & свекврва \\
\hline
\end{tabular}




\begin{tabular}{|c|c|c|}
\hline $\begin{array}{l}\text { Цифров } \\
\text { код на } \\
\text { референта }\end{array}$ & Неелементарна реверсивна семема, представяща референта & $\begin{array}{l}\text { Езиков знак, } \\
\text { представящ } \\
\text { референта }\end{array}$ \\
\hline 28 & 'майка на съпругата' & mzщза \\
\hline 41 & 'сестра на бащата' & леля \\
\hline 42 & 'сестра на майката' & леля \\
\hline 47 & 'сестра на съпруга' & зәлва \\
\hline 48 & 'сестра на съпругата' & балдвза \\
\hline 63 & 'дъщеря на брата’ & племенница \\
\hline 64 & 'дъщеря на сестрата' & племенница \\
\hline 65 & 'дъщеря на сина' & внучка \\
\hline 66 & 'дъщеря на дъщерята' & внучка \\
\hline 83 & 'съпруга на брата' & снаха \\
\hline 85 & 'съпруга на сина' & снаха \\
\hline 211 & 'майка на бащата на бащза; майка на дядото (по баща) & прабаба \\
\hline 212 & 'майка на бащата на майка; майка на дядото (по майка)' & прабаба \\
\hline 221 & 'майка на майката на бащза; майка на бабата (по баща)' & прабаба \\
\hline 222 & 'майка на майката на майка; майка на бабата (по майка)' & прабаба \\
\hline 276 & 'майка на зетя' & сватя \\
\hline 285 & 'майка на снахата' & сватя \\
\hline 417 & 'сестра на бащата на съпруг; сестра на свекъра' & ○лалка \\
\hline 483 & $\begin{array}{c}\text { 'сестра на снахата от брат; сестра на съпругата на } \\
\text { брат' }\end{array}$ & ○ свашка \\
\hline 485 & 'сестра на снахата от син; сестра на съпругата на син' & ○свашка \\
\hline 631 & 'дъщеря на брата на баща; дъщеря на чичото' & братовчедка \\
\hline 632 & ‘дъщеря на брата на майка; дъщеря на вуйчото’ & братовчедка \\
\hline 637 & 'дъщеря на брата на съпруг; дъщеря на девера' & $\begin{array}{l}\text { о деверич- } \\
\text { ница }\end{array}$ \\
\hline 641 & 'дъщеря на сестрата на баща; дъщеря на лелята' & братовчедка \\
\hline 642 & 'дъщеря на сестрата на майка; дъщеря на лелята' & братовчедка \\
\hline 647 & 'дъщеря на сестрата на съпруг; дъщеря на зблвата' & О зблвичница \\
\hline 655 & 'дъщеря на сина на син' & правнучка \\
\hline 656 & 'дъщеря на сина на дъщеря’ & правнучка \\
\hline 665 & 'дъщеря на дъщерята на син’ & правнучка \\
\hline 666 & 'дъщеря на дъщерята на дъщеря' & правнучка \\
\hline 831 & ‘съпруга на брата на бащза; съпруга на чичото’ & стринка \\
\hline 832 & ‘съпруга на брата на майка; съпруга на вуйчото’ & вуйна \\
\hline 837 & 'съпруга на брата на съпруг; съпруга на девера' & етврва \\
\hline 838 & 'съпруга на брата на съпругата; съпруга на журея' & иуренайка \\
\hline
\end{tabular}


Неелементарните семеми на РН, поместени в Таблици № 5, № 6 и № 7, са от по-особен, усложнен тип.

Реверсивните семеми на РН на деца (вж. Таблици № 5 и № 6) са построени по модела $X$ по отношение на $Y$, при който първата част на дефиницията (за разлика от тази на $\mathrm{PH}$, описани в Таблици № 1 и № 2) следва посесивната схема $а$ на в, където $a$ е винаги просто $\mathrm{PH}$ - син или дъщеря, а в може да бъде както единичен референт (напр. при референт с цифров код $5 \bullet, 5 \bullet, 6 \bullet$ и 6•), така и двойка референти (напр. при референт с цифров код 5.(9+89), 5. $(99+8.99), 6 .(9+89)$ и $6 .(99+8.99)$.

Таблица 5. Неелементарни РН за деца от мъжки пол

\begin{tabular}{|c|c|c|}
\hline $\begin{array}{c}\text { Цифров } \\
\text { код на } \\
\text { референта }\end{array}$ & Неелементарна реверсивна семема, представяща референта & $\begin{array}{c}\text { Езиков знак, } \\
\text { представящ } \\
\text { референта }\end{array}$ \\
\hline $5 \bullet$ & $\begin{array}{l}\text { 'дете (син) от предишен брак на жена, встъпила в нов } \\
\text { брак, по отношение на настоящзя й мъж' }\end{array}$ & доведеник \\
\hline $5^{\bullet}$ & $\begin{array}{c}\text { 'дете (син) от предишен брак на мъж, встъпил в нов брак, } \\
\text { по отношение на настоящата мужена' }\end{array}$ & завареник \\
\hline 5. $(9+89)$ & 'дете (син) на кума и кумата по отношение на кумците’ & ○ кумче \\
\hline 5.(99+8.99) & $\begin{array}{c}\text { 'дете (син) на кумеца и кумицата по отношение на кумо- } \\
\text { вете' }\end{array}$ & о кумичле \\
\hline
\end{tabular}

Таблица 6. Неелементарни РН за деца от женски пол

\begin{tabular}{|c|c|c|}
\hline $\begin{array}{l}\text { Цифров } \\
\text { код на } \\
\text { референта }\end{array}$ & Неелементарна реверсивна семема, представяща референта & $\begin{array}{c}\text { Езиков знак, } \\
\text { представящ } \\
\text { референта }\end{array}$ \\
\hline $6 \bullet$ & $\begin{array}{c}\text { 'дете (дъщеря) от предишен брак на жена, встъпила в нов } \\
\text { брак, по отнощение на настоящия иे мәж' }\end{array}$ & доведеница \\
\hline $6^{\bullet}$ & $\begin{array}{c}\text { 'дете (дъщеря) от предишен брак на мъж, встъпил в нов } \\
\text { брак, по отношение на настоящзата му жена' }\end{array}$ & завареница \\
\hline 6. $(9+89)$ & $\begin{array}{c}\text { 'дете (дъщеря) на кума и кумата по отношение на кум- } \\
\text { цзите’ }\end{array}$ & ○ кумка \\
\hline 6.(99+8.99) & $\begin{array}{c}\text { 'дете (дъщеря) на кумеца и кумицата по отношение на } \\
\text { кумовете' }\end{array}$ & ○ кумичка \\
\hline
\end{tabular}

Реверсивните семеми на РН на двойка лица (с изключение на съпрузи и годеници - вж. Таблица № 7) също са построени по модела $X$ по отношение на $Y$, като първата част на дефиницията обаче е изградена по схемата двойка тица $z_{1} u z_{2}$. Роднинските названия съпрузи и годенищи 
са представени сред останалите dualia tantum ${ }^{3}$, тъй като всеки член на това определено множество се съотнася с другия член по модела $X$ no отношение на $Y$.

\section{Таблица 7. Неелементарни РН за двойка лица}

\begin{tabular}{|c|c|c|}
\hline $\begin{array}{l}\text { Цифров } \\
\text { код на } \\
\text { референта }\end{array}$ & Неелементарна реверсивна семема, представяща референта & $\begin{array}{c}\text { Езиков знак, } \\
\text { представящ } \\
\text { референта }\end{array}$ \\
\hline$(1+2)$ & $\begin{array}{c}\text { 'двойка лица баща и майка по отношение на свочте } \\
\text { деца' }\end{array}$ & родители \\
\hline$(7+8)$ & 'семейна двойка лица съпруг и съпруга' & conpyзu \\
\hline$(7 \bullet+8 \star)$ & 'предбрачна двойка лица годеник и годеница' & годеници \\
\hline$(9+89)$ & 'двойка лица кум и кума по отношение на своите кумци' & кумове \\
\hline$(99+8.99)$ & $\begin{array}{c}\text { 'двойка лица кумец и кумица по отночение на свочте } \\
\text { кумове' }\end{array}$ & кумиц \\
\hline$(176+276)$ & $\begin{array}{c}\text { 'двойка лица сват и сватя по отношение на свочте сва- } \\
\text { тове }(185+285) \text { ' }\end{array}$ & сватове \\
\hline$(185+285)$ & $\begin{array}{c}\text { 'двойка лица сват и сватя по отночение на свочте сва- } \\
\text { тове }(176+276) \text { ' }\end{array}$ & сватове \\
\hline
\end{tabular}

Както се вижда, в Семантичния речник на елементарните и неелементарните $\mathrm{PH}$, назоваващи конкретни тица, подходът при характеризиране на референтите е от знанието за референта (за който има езиков знак в БЕ) през дешифриране на цифровия код (идеалния роднински термин) до езиковата единица (роднинското название). Семантичният речник представя 111 конкретни референти роднини (мъже, жени, деца и двойки лица), за които има поне едно название. От тях $50 \mathrm{ca}$ за лица с кръвно родство, а 61 - за лица с некръвно родство. ${ }^{4}$ По този начин Речникът очертава системата от РН на конкретни лица в БЕ.

3 Ако в речниците и в граматиките подобни единици са определени като форми на „съответните“ съществителни от м.р., тук те се представят като самостоятелни лексеми, тъй като притежават по-различни признаци, а именно - количествена определеност, неброимост и делимост, а показателят за число (-u, -ове) е функционално преобразуван, трансформиран в суфикс със значение 'двойка лица (мъж и жена)'. (Повече за граматичната и словообразувателната специфика на съществителните dualia tantum вж. Георгиева, 2010, 2012.)

${ }^{4}$ Вж. Приложение № 3 и № 4 в монографията. 
Представеният Семантичен речник може да послужи за изготвяне на двуезични и многоезични лексикографски трудове, в които цифровият код ще изпълнява функция на tertium comparationis.

Речникът може да се допълва, в случай че се открият в бъдеще названия, назоваващи нов референт роднина, а също и да бъде разширен, като даден референт роднина се представи детайлно по различни признаци (напр. по признака възраст - «по-млад〉/〈по-стар〉). Семантичният речник на елементарните и неелементарните роднински названия, назоваващи конкретни лица, може да бъде основа за изготвяне и на идеографски речници, както и на лексикалносемантични съпоставителни изследвания.

\section{Библиография}

Георгиева, Ц. (2010). Асиметрия в значенията при някои съществителни имена в българския език с оглед представянето им в лексикографските трудове. In Л. Крумова-Цветкова, Ц. Аврамова, Ц. Георгиева, \& Х. Холиолчев (Eds.), Слово и словесност: Сборник в чест на дои. д-р Юлия Балтова (рр. 68-76). София: Емас.

Георгиева, Ц. (2012). Названия на двойка лица (мъж и жена) и тяхното място в езиковата система и текста (в българския език в съпоставка с други езици). In Słowotwórstwo słowiańskie: system i tekst: Prace Komisji Słowotwórczej przy Międzynarodowym Komitecie Slawistów: Seria 13 (pp. 55-66). Poznań: Wydawnictwo PTPN.

Георгиева, Ц. (2016а). Родството и роднинските названия в българския език (семантика и лексикографско представяне). София: Авангард Прима.

Георгиева, Ц. (2016b). Цифровият код в речника „Българска семейно-родова лексика“. Български език, 2016(3), 97-108.

Левин, Ю. И. (1970). Об описании системы терминов родства. Советская этнография, 1970(4), 18-30.

Морган, Л. Г. (1939). Първобитното общество: Линиите на човешкия прогрес от дивачеството, през варварството до цивилизацията (М. Марчевски, Trans.). София. (Original work published 1877).

Попова, М. (2012). Теория на терминологията (Vol. 1). Велико Търново: Знак '94.

Източници

Холиолчев, Х., Младенов, М., \& Радева, Л. (2012). Българска семейно-родова лексика: Енциклопедичен речник [БСРЛ]. София: Изток - Запад. 


\section{Bibliography (Transliteration)}

Georgieva, T. (2010). Asimetriia v znacheniiata pri niakoi sŭshtestvitelni imena v bŭlgarskiia ezik s ogled predstavianeto im v leksikografskite trudove. In L. Krumova-TSvetkova, T. Avramova, T. Georgieva, \& K. Kholiolchev (Eds.), Slovo i slovesnost: Sbornik $v$ chest na dots. d-r IUliia Baltova (pp. 68-76). Sofiia: Emas.

Georgieva, T. (2012). Nazvaniia na dvoǔka litsa (mŭzh i zhena) i tiakhnoto miasto v ezikovata sistema i teksta (v bŭlgarskiia ezik v sŭpostavka s drugi ezitsi). In Słowotwórstwo słowiańskie: system i tekst: Prace Komisji Słowotwórczej przy Międzynarodowym Komitecie Slawistów: Seria 13 (pp. 55-66). Poznań: Wydawnictwo PTPN.

Georgieva, T. (2016a). Rodstvoto i rodninskite nazvaniia v bŭlgarskiia ezik (semantika i leksikografsko predstaviane). Sofiia: Avangard Prima.

Georgieva, T. (2016b). TSifroviiat kod v rechnika "Bŭlgarska semeŭno-rodova leksika". Bŭlgarski ezik, 2016 (3), 97-108.

Levin, I. I. (1970). Ob opisanii sistemy terminov rodstva. Sovetskaia ètnografiia, 1970 (4), 18-30.

Morgan, L. G. (1939). Pŭrvobitnoto obshtestvo: Liniite na choveshkiia progres ot divachestvoto, prez varvarstvoto do tsivilizatsiiata (M. Marchevski, Trans.). Sofiia. (Original work published 1877).

Popova, M. (2012). Teoriia na terminologiiata (Vol. 1). Veliko Tŭrnovo: Znak'94.

\section{Sources}

Kholiolchev, K., Mladenov, M., \& Radeva, L. (2012). Bŭlgarska semeĭno-rodova leksika: Entsiklopedichen rechnik [BSRL]. Sofia: Iztok - Zapad.

\section{Semantic dictionary of kinship denominations in the Bulgarian language}

\section{Summary}

The article is a presentation of Semantic dictionary of kinship denominations in the Bulgarian language, which is integral part of my monograph Kinship and kinship denominations in the Bulgarian language (semantics and lexicographic presentation). The dictionary is organized according to digital 
codes (ideal terms), then a metalanguage in the form of definitions, and finally the particular language signs themselves. 111 particular kinship-related referents are presented (men, women, children and couples), for whom we have at least one denomination. The article provides information about a range of potential theoretical and scientific applications of the dictionary.

\section{Semantyczny słownik nazw stopnia pokrewieństwa $\mathrm{w}$ języku bułgarskim}

\section{Streszczenie}

Artykuł jest prezentacją Semantycznego słownika nazw stopni pokrewieństwa w języku bułgarskim, stanowiącego integralną część mojej monografii Pokrewieństwo i nazwy stopni pokrewieństwa w języku bułgarskim (semantyka i opis leksykograficzny). Słownik zorganizowany jest według kodów cyfrowych (terminy idealne), następnie według tworzących metajęzyk definicji, w końcu zaś według samych poszczególnych znaków językowych. Prezentuję w nim 111 desygnatów-stopni pokrewieństwa, dla których dysponujemy choć jedną nazwą (kobiety, mężczyzny, dziecka czy pary). Artykuł wskazuje także szereg potencjalnych teoretycznych i naukowych zastosowań słownika.

Keywords: semantic dictionary of kinship denominations; Bulgarian language; digital code

Słowa kluczowe: semantyczny słownik nazw stopni pokrewieństwa; język bułgarski; kod cyfrowy

\footnotetext{
Tsvetelina Georgieva, Professor Lyubomir Andreychin Institute for the Bulgarian Language, Bulgarian Academy of Sciences, Sofia

Correspondence: cveti.g@abv.bg

The preparation of this article was self-financed.

Competing interests: The author has declared she has no competing interest.
} 